\title{
ПОНЯТИЕ И ТЕХНОЛОГИЯ КРИМИНАЛИСТИЧЕСКОГО РАСПОЗНАВАНИЯ САМОУБИЙСТВА
}

\author{
А.В. Бертовский, И.В. Глазунова, И.В. Маслов \\ Юридический институт ФГАОУ ВО „Российский университет дружбы народов», г. Москва, Россия \\ ФГБУН “Институт государства и права Российской академии наук», г. Москва, Россия \\ ФГБОУ ВО "Государственный университет управления", г. Москва, Россия \\ Институт экономики и культуры, г. Москва, Россия
}

Контактная информация:

Бертовский $е$ ев ВАадимирович - доктор юридических наук, профессор (SPIN-код: 7788-0864; ORCID iD: 0000-00022835-288X; Researcher ID: P-7579-2015). Место работы и должность: профессор кафедры уголовного права, уголовного процесса и криминалистики Юридического института ФГАОУ ВО “Российский университет дружбы народов". Адрес: Россия, 117198, г. Москва, ул. Миклухо-Маклая, д. 6. Телефон: (495) 434-41-12, вн. 11-44, эмектронный адрес: bgl1980@yandex.ru

ГАазунова Инесса Вцадимировна - кандидат юридических наук, доцент (SPIN-код: 3357-3008). Место работы и должность: старший научный сотрудник сектора административного права и административного процесса ФГБУН Институт государства и права Российской академии наук. Адрес: Россия, 119019, г. Москва, ул. Знаменка, д. 10. Телефон: (495) 691-33-81; доцент кафедры частного права ФГБОУ ВО "Государственный университет управления". Адрес: 109542, Москва, Рязанский проспект, 99. Темефон: (495) 377-89-14; электронный адрес: ginesa@mail.ru

Маслов Игорь Викторович - кандидат юридических наук (SPIN-код: 7668-9439, AuthorID: 379390). Место работы и должность: доцент кафедры уголовно-правовых дисциплин Института экономики и культуры. Адрес: Россия, 105318, г. Москва, ул. Ибрагимова, д. 31, корп.1. Темефон: (495) 795-00-11, эмектронный адрес: igormaslof@rambler.ru

Целью исследования является рассмотрение возможных направлений интеграции наук криминалистики и суицидологии в распознавании самоубийств. Материал и методы: проведён системный анализ разработанных в криминалистике теоретических основ выявления самоубийств. Использован эмпирический материал архивов следственных подразделений, а также специальной литературы, средств массовой информации. Результаты: Опираясь на положения учения о криминалистическом распознавании, предложена идея создания технологии получения уголовно-релевантных сведений, недоступных для непосредственного восприятия, через построение когнитивных моделей на основе следовой информации, выявленной на месте происшествия. На практических примерах демонстрируются трудности определения существующими методами уголовнопроцессуального познания субъективной стороны суицидального деяния. Предлагается классификация когнитивных моделей суицида и тактических комбинаций по распознаванию самоубийств. Отмечены неизбежные риски и допущения при построении моделей. Заключение. Предлагаются определения содержания терминов «криминалистическое распознавание» и «криминалистическое распознавание самоубийств»; структура учения о криминалистическом распознавании; рекомендации по единой тактической операции выявления убийств, самоубийств и несчастных случаев.

Ключевые слова: самоубийство, криминалистика, суицидология, криминалистическое распознавание, междисциплинарные исследования

Первостепенно знание для прикладных наук является создание полезных, применимых в практической деятельности моделей, объясняющих то или иное явление [1]. С точки зрения решения прикладных задач уголовного судопроизводства и дальнейшего развития наук уголовно-правового цикла, важнейшее значение приобретает интеграция знаний и поиск направлений взаимодействия, в частности криминалистики и суицидологии [2]. Это утверждение справедливо для криминалистического распознавания суицидов, что возможно путём создания когнитивной модели, позволяющей достигнуть на практике определённого результата [3]. В теории криминалистики распознавание представлено в виде определённой технологии: системы процессуальных и непроцессуальных действий, направленных на получение знания о познаваемом объекте, недоступном для чувственного восприятия, путём собирания, проверки, исследования и оценки информации и сопоставления её с модельной уголовно - релевантной информацией и использование полученного знания для доказывания в уголовном процессе [4].

Вместе с тем возникает ряд вопросов: 
1. До какой степени событие, явление должно быть недоступным для чувственного восприятия? Здесь речь идёт о субъективной мотивации действий погибшего?

2. На чём основывается модельная информация, и какова её достоверность?

3. Каким образом производится отбор информации, используемой для построения модели события? По сути, построение модели есть ни что иное как информационное упрощение, когда в модель закладываются только сведения, признанные исследователем значимыми, и отвергаются все иные сведения, признанные по тем или иным причинам нерелевантными, относительно события.

Первый вопрос актуален в свете того, что на сегодняшний момент системы аудио- и видеофиксации чрезвычайно развиты и распространены. Под объективы попадают и убийства, и самоубийства, и кражи, и повреждения имущества и нарушения процедуры выборов, и бесчисленное множество иных событий. Самоубийство, совершённое при включенной записи на видеокамеру, при всей кажущейся очевидности всё равно подлежит распознаванию. В этом случае важно установить, в том числе для принятия мер профилактического характера, следствием чего именно является самоубийство, не скрываются ли за произошедшим криминальные обстоятельства. Но всё это находится «за кадром».

Следует отметить, что в настоящее время не имеется государственного или общественного института, к задачам которого отнесены выявление причин самоубийств и разработка мер их профилактики. Самоубийства, в большинстве своём, выявляются следователями Следственного комитета Российской Федерации.

По окончании предварительного расследования в порядке, предусмотренном ч. 2 ст. 158 УПК РФ, следователь вправе внести в соответствующую организацию или соответствующему должностному лицу представление о принятии мер по устранению обстоятельств, способствовавших совершению преступления или других нарушений закона. При этом внесение представления по факту самоубийства, установленного в рамках доследственной проверки с последующим отказом в возбуждении уголовного дела, следует признать не предусмотренным законом. Во-первых, ст. 158 УПК РФ называется «Окончание предварительного расследования», следовательно, представление может вноситься только по возбуждённому уголовному делу до его прекращения, либо направления прокурору с обвинительным заключением. Во-вторых, в указанной норме говорится о причинах и условиях, способствовавших совершению преступления, а самоубийство преступлением не признаётся. Втретьих, профилактика самоубийств, равно как и преступлений, не относится к функции следователя, и зачастую в представлении излагаются установленные обстоятельства и «назначается» лицо, не принявшее профилактических мер. Однако при покушении на самоубийство, именно тогда, когда меры профилактики действительно необходимы, какиелибо профилактические меры вообще не применяются.

Характерным примером трудности установления субъективной стороны события гибели человека служит смерть 32-летнего видеоблогера и герпетолога (специалиста в области зоологии, изучающей земноводных и пресмыкающихся) В. [5]. В рамках онлайн трансляции, сидя за рабочим столом, В. сказал: «Ну, чего, чуваки? Пора делать то, что надо делать». Затем вышел из кадра, где, как установлено, получил укус черной мамбы - одной из самых ядовитых змей, произнес: «Ай! Отпусти, больно. Молодец, убила меня. Пойду трансляцию вести. Умру, так умру». После этого, не предприняв мер для того, чтобы предотвратить действие яда, сразу вошёл «в кадр», сказал, что «если что, на телефоне запись для К.», которая приходилась ему бывшей женой, с которой он расстался незадолго до смерти, и начал читать комментарии. При этом поведение В. свидетельствовало об ухудшении его самочувствия. С точки зрения уголовно-правового познания, во-первых, возникает вопрос о роде смерти (самоубийство или несчастный случай); вовторых, о возможном наличии в обстоятельствах, которые привели к смерти, криминального компонента (в данном случае наиболее вероятным проявление криминального компонента представляется доведение до самоубийства) и т.д.

Таким образом, более корректно говорить не о недоступности для чувственного восприятия вообще, а о недоступности для чувственного восприятия именно комплекса обстоятельств, необходимого для юридической оценки события - субъективной стороны деяния, психологических процессов, протекавших в воле и сознании В. в момент получения укуса. 
Отвечая на второй вопрос, заранее оговорим, что под модельной информацией следует понимать определённые мыслеобразы, связанные с уголовно-релевантным событием. При квалификации случаев смерти будет иметь место применение сразу нескольких типовых моделей:

- правовая (содержание УК РФ и актов толкования);

- житейско-профессиональная (модель, сложившаяся у лица на основе его житейского и профессионального опыта);

- криминалистическая (научно выявленные типовые криминалистические характеристики, криминалистические признаки события).

Сопоставление моделей между собой, либо сопоставление реальных событий / объектов / явлений с данными моделями является сутью сравнительного метода [6], играющего значительную роль в технологии криминалистического распознавания. Вместе с тем чрезмерный акцент следователя в практической деятельности на житейско-профессиональные модели может оказаться пагубным. Так, житейские представления, свойственные сотрудникам правоохранительных органов, могут существенно отличаться от объективных научных данных. Криминалистические модели базируются на результатах научных исследований, а потому обладают более высоким уровнем объективности, находят своё место в криминалистической характеристике события.

Ответом на третий вопрос видится то, что отбор модели осуществляется при восприятии первичной информации. Например, в случаях самоубийств основой для поиска модельной информации является факт обнаружения трупа с признаками насильственной смерти, то есть смерти, наступившей от внешних воздействий. Характерно, что на профессиональном сленге сотрудников правоохранительных органов термин «насильственная смерть» имеет иное значение, а именно: смерть, наступившая от действий третьих лиц.

В качестве наиболее подходящей рабочей конструкции, в которой способна воплотиться технология криминалистического распознавания, справедливо предлагаются такие криминалистические средства, как тактическая операция и тактическая комбинация $[4,7]$.

Исходя из определений, разработанных в криминалистической науке $[8,9,10]$, под тактической операцией, следует понимать систему следственно-оперативных мероприятий, вклю- чающих различные тактические приёмы и комбинации, для достижения определённой локальной задачи исследования уголовнорелевантного события наиболее эффективным способом из тех, которые возможны в конкретной ситуации. Тактической комбинацией, в свою очередь, является набор тактических приемов, объединённых единой тактической задачей / целью, применяемый в рамках одного следственного / оперативно-розыскного мероприятия.

Тактические операции / комбинации, которые направлены на решение распознавательных задач, предлагается именовать распознавательными тактическими операциями / комбинациями.

Распознавательная задача двуедина и включает в себя установление:

- сущности, природы события / объекта / явления;

- уголовной релевантности (относимости) данного события / объекта / явления [11].

Установление релевантности (относимости) может осуществляться на двух уровнях:

- к конкретному уголовно-релевантному событию;

- к модели преступления, предусмотренной уголовным законом.

Распознавательные тактические операции, направленные на распознавание событий, могут иметь место в ряде основных случаев:

- на начальном этапе расследования, когда необходимо распознать природу события, отделив от иных смежных событий;

- в случае наличия предположения о том, что уже расследуемое событие содержит в себе элемент, сущность которого не раскрыта, не узнана в достаточной мере.

Примером случая, относящегося ко второй группе как гораздо более редкой, является происшествие, имевшее место в Китае, когда мужчина нанял другое лицо с помощью сети «Интернет» для убийства самого себя, за что предложил около 11 тыс. долларов США. Решение заказчика покончить с собой было обусловлено невозможностью передвигаться самостоятельно вследствие травмы, полученной за несколько лет до происшествия. Мужчины встретились в хостеле, где исполнитель ножом нанес заказчику 12 ударов в живот. Однако заказчик от боли начал звать на помощь, после чего виновный бросил оружие и покинул место происшествия [12]. 
На основании вышеизложенного можно сделать вывод о том, что криминалистическое распознавание - это технология (тактическая операция / комбинация), направленная на установление сущности, природы, события (объекта, явления) в условиях их недоступности для чувственного восприятия, которая осуществляется путём собирания, проверки, исследования, оценки фактической информации и сопоставления её с модельной информацией.

В целом, предлагается следующая структура учения о криминалистическом распознавании [13]:

1. Общие положения теории криминалистического распознавания

- понятие, объект, предмет, цель, задачи, принципы, функции, методология учения;

- место учения в системе криминалистической науки, системе криминалистических учений, взаимосвязь криминалистического учения о распознавании с иными учениями, науками;

- понятийный аппарат учения; критерии классификации распознавательных задач.

2. Прикладные аспекты и направления реализации положений теории криминалистического распознавания:

- методы и средства криминалистического распознавания;

- типизация и классификация распознавательных задач;

- основы методики и технологии криминалистического распознавания; направления оценки и использования полученной информации в выявлении, раскрытии и расследовании преступления.

Применение технологии криминалистического распознавания как формы криминалистического обеспечения исследования смертельного случая, очевидно, возможно в отношении такого уголовно-релевантного явления как самоубийство. В этой связи уместно поднять вопрос о соответствующей тактической операции.

Таким образом, для случаев, когда имеются основания предполагать, что исследуемый случай смерти является самоубийством, предлагается типовая криминалистическая тактическая операция «Распознавание самоубийства» (далее - ТО «РС»), включающая в себя набор средств, способствующих обеспечению полноценного исследования и оценки события.

Посредством ТО «РС» будет решаться вопрос о сущности смертельного случая (роде смерти) и наличии в обстоятельствах произошедшего криминального компонента. ТО «РС» может найти применение, в том числе, при выявлении инсценировок, а также в ситуациях, когда по ряду причин смерть напоминает самоубийство, но ею не является.

В случаях, когда особо проблематично распознать род смерти (так называемые «загадочные смерти» [5]), ТО «РС» рекомендуется включить в общий блок производимых следственно-оперативных мероприятий. Например, отечественные и австралийские криминалисты к случаям, когда распознать род смерти (в том числе, самоубийство) затруднительно, относят случаи смерти при дорожно-транспортных происшествиях, случаи передозировок наркотическими средствами [14], случаи, связанные с поджогами и взрывами помещений [15].

Примерами, когда ТО «РС» осуществляется на более поздних этапах расследования, могут являться те случаи смерти, когда самоубийство фактически включает в себя элемент гомицида (например, когда человек нанимает другое лицо для причинения себе смерти, либо в случаях «самоубийств с помощью полицейского», более распространённых в западных странах, когда лицо провоцирует сотрудников полиции, чтобы те применили к нему оружие на поражение).

Пример, демонстрирующий возможный вариант самоубийства с «помощью» полицейского, имеется в американской криминалистической литературе. Так, женщина вызвала полицию в связи с тем, что бывший муж ворвался к ней домой. По прибытии полиция услышала крики из подвала. Спускаясь по лестнице, сотрудники полиции увидели молодого человека, держащего ружье. Увидев полицейских, он начал медленно направлять ствол в их сторону. Оба полицейских выстрелили, убив его. Однако ружьё убитого оказалось не заряжено [16].

В ряде случаев, в силу процессуальных ограничений, возникает необходимость возбудить уголовное дело, чтобы обладать более массивным инструментарием для разрешения следственной ситуации. К такому инструментарию относятся мероприятия, не входящие в перечень проверочных, которые предусмотрены ч. 1 ст. 144 УПК РФ: следственный эксперимент; получение информации о соединениях между абонентами и т.д.

Спустя более чем год (!) после падения из окна подъезда между 4 и 5 этажами П., пере- 
двигавшегося с трудом инвалида, возбуждено уголовное дело по признакам убийства. Ранее в возбуждении дела было отказано в связи с отсутствием события преступления, а происшествие признано самоубийством. На месте происшествия отсутствовали следы борьбы, окно было открыто, тапочки погибшего находились на лестничной площадке. В ходе расследования по возбуждённому делу, кроме прочего, произведён следственный эксперимент, в рамках которого с помощью манекена смоделировано падение погибшего. Результаты следственного эксперимента впоследствии были использованы при проведении комплексной медикокриминалистической и трасологической экспертизы, выявившей, что к телу погибшего при падении приложена сила. Кроме того, в ходе дальнейшего расследования было установлено множество очевидцев, которые сообщили не только оба обстоятельствах гибели, но и поспособствовали установлению виновного лица [17], что указывает на недостаточное внимание к случаям, внешне напоминающих самоубийство.

Причиной осуществления ТО «РС» на более поздних стадиях расследования может являться то, что наличие суицидальных намерений у лица является далеко не явным, как в приведённом выше случае, произошедшем в Китае.

Интерес здесь также представляют различные примеры из практики расследования уголовных дел об убийствах, когда причина наступления смерти не является однозначно установленной, и обвиняемое в убийстве лицо утверждает, что имело место не инкриминируемое ему убийство, а самоубийство.

В кассационном представлении поставлен вопрос об отмене оправдательного приговора в отношении К., обвинявшегося по ч. 1 ст. 105 УК РФ. Прокурор ссылается, в том числе, на то, что вывод суда о совершении потерпевшей самоубийства основан на показаниях заинтересованных лиц - родственников оправданного о склонности погибшей к суициду; при этом суд не дал оценки показаниям работников социального учреждения об отсутствии у потерпевшей суицидальных намерений, об относительной малоподвижности погибшей в силу её возраста, об имевшейся у неё проблеме, связанной с моторикой рук, её неспособностью завязывать узлы; что показания специалистов о причинении погибшей перелома подъязычной кости путём давления рукой на шею не согласуются с мнением комиссии экспертов; что по ряду вопросов имелись противоречия, в том числе о механизме причинения перелома подъязычной кости потерпевшей и давности образования телесных повреждений [18]. В указанном случае прослеживаются недостатки проработки версии о самоубийстве на предыдущих процессуальных стадиях.

Таким образом, ТО «РС» можно классифицировать в зависимости от того, на какой процессуальной стадии (этапе) начинается её реализация:

- на этапе проверки сообщения о преступлении (до возбуждения уголовного дела);

- на стадии предварительного расследования.

Данное деление обусловлено тем, что: вопервых, до возбуждения уголовного дела фактический материал собирается «с нуля», версии практически не проверены, в то время как во втором случае уже собрана некоторая информация о произошедшем, и ряд версий уже в той или иной мере проверены; во-вторых, уголовно-процессуальный закон на сегодняшний день предусматривает хотя и аналогичные, но несколько различающиеся возможности для получения информации на данных стадиях.

ТО «РС» нацелена на выявление как можно более полной информации для решения вопроса о наибольшей вероятности того, могло ли в данном случае иметь место самоубийство.

ТО «РС» применима преимущественно к случаям, когда сам способ совершения самоубийства не является криминальным (под случаями криминального самоубийства, в частности, подразумеваются суицидальные террористические акты), однако ТО «РС» применима и к случаям самоубийства, совершенными общеопасным способом.

Таким образом, криминалистическое распознавание самоубийства - это направленная на установление рода смерти и наличие / отсутствие в обстоятельствах смерти с признаками самоубийства состава преступления технология собирания, проверки, исследования, оценки субъектом поисково - познавательной деятельности фактической информации и сопоставления её с модельной информацией при недоступности для чувственного восприятия комплекса сведений, необходимого для юридической оценки исследуемого события.

Криминалистическое распознавание самоубийства можно рассматривать в качестве со- 
ставной части криминалистического распознавания смертельных случаев вообще, которое, в свою очередь, способно выступить составной частью методики расследования смертельных случаев. Создание такой методики представляется перспективным направлением развития криминалистической методики, особенно с учетом статуса подобных методик за рубежом.

Рассматриваемая методика преимущественно распространяется на такие преступления, как: убийство (ст.ст. 105-108 УК РФ), причинение смерти по неосторожности (ст. 109 УК РФ), доведение до самоубийства (ст. 110 УК РФ), склонение к совершению самоубийства и содействие его совершению, повлекшие самоубийство или покушение на таковое (ч.ч. 4-6 ст. 110 УК РФ), умышленное причинение тяжкого вреда здоровью, повлекшее по неосторожности смерть потерпевшего (ч. 4 ст. 111 УК РФ), нарушение требований охраны труда, совершённое лицом, на которое возложены обязанности по их соблюдению, повлекшее по неосторожности смерть человека / людей (ч.ч. 2, 3 ст. 143 УК РФ) и др., которые можно сгруппировать в зависимости от распознанного рода смерти.

Комплексный подход к расследованию смертельных случаев имел место ещё на заре

\section{Литература:}

1. Лебедев С.А. Философия науки: краткая энциклопедия (основные направления, концепции, категории). М.: Академический проект, 2008. 692 с.

2. Лисовецкий А.Л. Бертовский Л.В., Поздняков В.М. Суицидология и криминалистика: пути взаимодействия. Суицидология. 2018; 9 (1): 80-86.

3. Шмонин А.В. Криминалистическая тактика и технология. Криминалистическая тактика: современное состояние и перспективы развития: Сборник материалов 56-х криминалистических чтений: В 2-х ч. Ч. 2. М., 2015: 317.

4. Корма В.Д., Образцов В.А. Криминалистическое распознавание: теория, метод, модели технологий. М.: Юрлитинформ, 2014. $416 \mathrm{c}$.

5. Несчастный случай или суицид: СК выясняет обстоятельства смерти блогера-серпентолога http://www.ntv.ru/novosti/1933594/ (Дата обращения 24.02.2019)

6. Бертовский Л.В. Расследование преступлений экономической направленности. М.: Проспект, 2016. 299 с.

7. Корма В.Д., Образцов В.А. Проблемы и пути совершенствования парадигмы криминалистического распознавания. Актуальные проблемь российского права. 2015; 7 (56): 158-168.

8. Баев О.Я. Криминалистика. Лекционный курс. М.: Юстиция, 2017.

9. Корноухов В.Е. Методика расследования преступлений: теоретические основы. Монография. М.: Норма: НИЦ ИНФРА-M, 2014. 224 c.

10. Криминалистика / Под общ. ред. А.И. Бастрыкина. Т. II. М.: Экзамен, 2014. 559 с.

11. Колдин В.Я. Криминалистический анализ. М.: Юрлитин- криминалистической науки [19]. Анализ зарубежной (в частности, американской и немецкой) литературы демонстрирует существование и в настоящее время данного подхода к расследованию случаев смерти. Так, частью методики расследования убийств (гомицидов) ${ }^{l}$ в США является методика расследования самоубийств [20]. В свою очередь, немецкая криминалистика изучает расследование смертельных случаев в целом, включая убийства, самоубийства, несчастные случаи [21]. Криминалистическое распознавание смертельного случая здесь наиболее ярко может проявляться на начальном этапе расследования, включая стадию возбуждения уголовного дела.

${ }^{I}$ Отечественная криминалистическая методика является ближайшим аналогом теории расследовании преступлений (США) и специальной криминалистики (ФРГ). Таким образом, указанные разделы для лучшего понимания русскоязычными читателями автором отнесены к криминалистической методике. Следует иметь в виду, что в криминалистике США следует отметить некоторое различие между теорией расследовании гомицидов (случаев причинения смерти другим лицом), преимущественно предназначенной для агентов обвинительной власти, и теорией расследования случаев смерти, предназначенной для коронеров и медиков-дознавателей, выступающих нейтральными в процессуальном отношении лицами.

References:

1. Lebedev S.A. Filosofiya nauki: kratkaya enciklopediya (osnovnye napravleniya, koncepcii, kategorii) [Philosophy of science: a brief encyclopedia (basic directions, concepts, categories)]. M.: Akademicheskij proekt, 2008. 692 c. (In Russ)

2. Lisovetski A.L., Bertovsky L.V., Pozdnyakov V.M. Suicidology and criminalistics: ways of interaction. Suicidology. 2018; 9 (1): 80-86. (In Russ)

3. Shmonin A.V. Kriminalisticheskaya taktika i tekhnologiya. Kriminalisticheskaya taktika: sovremennoe sostoyanie i perspektivy razvitiya [Forensic tactics and technology. Forensic tactics: current state and development prospects]: Sbornik materialov 56-h kriminalisticheskih chtenij: B 2-х ч. Ч. 2. M., 2015: 317. (In Russ)

4. Korma V.D., Obrazcov V.A. Kriminalisticheskoe raspoznavanie: teoriya, metod, modeli tekhnologij [Forensic face recognition: theory, method, model, technology]. M.: Yurlitinform. M.: Юpлитинформ, 2014. 416 с. (In Russ)

5. Neschastnyj sluchaj ili suicid: SK vyyasnyaet obstoyatel'stva smerti blogera-serpentologa [Accident or suicide: SK finds out circumstances of death of blogger's serpentlike] // http://www.ntv.ru/novosti/1933594/ (In Russ)

6. Bertovskij L.V. Rassledovanie prestuplenij ekonomicheskoj napravlennosti [Investigation of economic crimes]. M.: Prospekt, 2016. 299 c. (In Russ)

7. Korma V.D., Obrazcov V.A. Problemy i puti sovershenstvovaniya paradigmy kriminalisticheskogo raspoznavaniya [Problems and ways of improving the paradigm of forensic recognition]. Aktual'nye problemy rossijskogo prava. 2015; 7 (56): 158-168. (In Russ)

8. Baev O.Ya. Kriminalistika. Lekcionnyj kurs [Criminalistics. Lecture course]. M.: Yusticiya, 2017. (In Russ)

9. Kornouhov V.E. Metodika rassledovaniya prestuplenij: teoreticheskie osnovy [Methods of investigation of crimes: a theoretical framework]. Monografiya. M.: Norma: NIC INFRA-M, 2014. 224 c. (In Russ)

10. Kriminalistika [Criminalistics] / Pod obshch. red. A.I. Bastrykina. T. II. M.: Ekzamen, 2014. 559 c. (In Russ)

11. Koldin V.Ya. Kriminalisticheskij analiz [Forensic analysis]. M.: 
форм, 2016. 528 с.

12. Китайский инвалид нанял киллера для убийства себя и передумал умирать после ран https://lenta.ru/news/2016/03/30/kill_me_no_stop/ (Дата обращения 24.02.2019).

13. Глазунова И.В. Криминалистическая теория распознавания Интерпретация основных понятий. Закон и право. 2018; 2 25-30.

14. Byard R. et al. Suicide in forensic practice - an Australian perspective. Australian Journal of Forensic Sciences. 2011; 43 (1): 72-73.

15. Выдрина И.В. Исходные доследственные ситуации по фактам самоубийств. Криминалистические методы расследования преступлений. Вып. 2. Тюмень, 1995. С. 47.

16. Suicide by Cop /https://pdfs.semanticscholar.org/e3e9/002efa7203bf48b7e12897 65e38e4d4a04d3.pdf

17. Яковлев Я.А. Физика помогла в раскрытии убийства. Предварительное следствие. 2012; 1 (15): 76-80.

18. Постановление Президиума Омского областного суда от 08.06.2015 № 44-У-32/2015. Справочная правовая система «КонсультантПлюс».

19. Гросс Г. Руководство для судебных следователей как система криминалистики. Новое изд., перепеч. с изд. 1908 г. М., 2002. $1088 \mathrm{c}$

20. Geberth V.J. Practical homicide investigation: tactics, procedures, and forensic techniques. $4^{\text {th }}$ ed. BocaRaton, 2006.

21. Сокол В.Ю. Криминалистика в Германии: понятие, система перспективы. Краснодар, 2010. 258 с.
Yurlitinform, 2016. 528 c. (In Russ)

12. Kitajskij invalid nanyal killera dlya ubijstva sebya i peredumal umirat' posle ran [Chinese invalid hired a killer to kill himself and changed his mind to die after the wounds] / https://lenta.ru/news/2016/03/30/kill_me_no_stop/. (In Russ)

13. Glazunova I.V. Kriminalisticheskaya teoriya raspoznavaniya. Interpretaciya osnovnyh ponyatij [Forensic theory of pattern recognition. The interpretation of the basic concepts]. Zakon i pravo. 2018; 2: 25-30. (In Russ)

14. Byard R. et al. Suicide in forensic practice - an Australian perspective. Australian Journal of Forensic Sciences. 2011; 43 (1): 72-73.

15. Vydrina I.V. Iskhodnye dosledstvennye situacii po faktam samoubijstv. Kriminalisticheskie metody rassledovaniya prestuplenij [Initial investigation of the situation on the facts of suicide. Forensic methods of crime investigation]. Vyp. 2. Tyumen', 1995. C. 47. (In Russ)

16. Suicide

$$
\text { by }
$$

Cop

/https://pdfs.semanticscholar.org/e3e9/002efa7203bf48b7e12897 65e38e4d4a04d3.pdf

17. Yakovlev Ya.A. Fizika pomogla v raskrytii ubijstva [Physics helped solve the murder]. Predvaritel'noe sledstvie. 2012; 1 (15): 76-80. (In Russ)

18. Postanovlenie Prezidiuma Omskogo oblastnogo suda ot [Resolution of the Presidium of the Omsk regional court from] 08.06.2015 № 44-U-32/2015. Spravochnaya pravovaya sistema «Konsul'tantPlyus». (In Russ)

19. Gross G. Rukovodstvo dlya sudebnyh sledovatelej kak sistema kriminalistiki [A guide for forensic investigators as a forensic science system]. Novoe izd., perepech. s izd. 1908 g. M., 2002. 1088 c. (In Russ)

20. Geberth V.J. Practical homicide investigation: tactics, procedures, and forensic techniques. $4^{\text {th }}$ ed. BocaRaton, 2006.

21. Sokol V.Yu. Kriminalistika v Germanii: ponyatie, sistema, perspektivy [Criminology in Germany: concept, system, prospects]. Krasnodar, 2010. 258 c. (In Russ)

\section{CONCEPT AND TECHNOLOGY OF CRIMINALISTIC RECOGNITION OF SUICIDE}

\section{L.V. Bertovsky ${ }^{1}$ I.V. Glazunova ${ }^{2}$, I.V. Maslov ${ }^{3}$}

${ }^{1}$ Russian Peoples' Friendship University, Moscow, Russia; bg11980@yandex.ru

${ }^{2}$ Institute of State and Law of The Russian Academy of Sciences, Moscow, Russia; State University of Management, Moscow, Russia; ginesa@mail.ru

3 Institute of Economics and Culture? Moscow, Russia; igormaslof@rambler.ru

\section{Abstract:}

The aim of the study is to examine the possible directions of integration of the sciences of criminology and suicidology in the recognition of suicide. Material and methods: a systematic analysis of the theoretical foundations of suicide detection in forensic science was carried out. Empirical material archives of investigative units, as well as special literature and the media were used. Results: Based on the provisions of the doctrine of forensic recognition, the idea of creating a technology for obtaining criminal-relevant information, that is not available for direct perception, is proposed through the construction of mental models based on trace information detected at the scene of the incident. The practical examples demonstrate the difficulty of determining the subjective side of a suicidal act by using the existing methods of criminal procedural knowledge. A classification of mental models of suicide and tactical combinations for the recognition of suicide are proposed. Inevitable risks and assumptions in building models are marked. Conclusion. The authors have offered the definition of the content of the terms "forensic recognition" and "forensic recognition of suicide"; structure of the theory of forensic recognition; recommendations for a single tactical operation to identify homicides, suicides and accidents.

Keywords: suicide, forensics, suicidology, forensic recognition, interdisciplinary research

Финансирование: Исследование не имело финансовой поддержки.

Конфмикт интересов: Авторы декларируют отсутствие явных и потенциальных конфмиктов интересов, о которых необходимо сообщить в связи с публикацией данной статьи.

Для цитирования: Бертовский Л.В., Глазунова И.В., Маслов И.В. Понятие и технология криминалистического распознавания самоубийства. Суицидология. 2019; 10 (1): 105-111. doi.org/10.32878/suiciderus.19-10-01(34)-105-111

For citation: $\quad$ Bertovsky L.V., Glazunova I.V., Maslov I.V. Concept and technology of criminalistic recognition of suicide. Suicidology. 2019; 10 (1): 105-111. (In Russ) doi.org/10.32878/suiciderus.19-10-01(34)-105-111 